\title{
EL COMPROMISO POLÍTICO: RAZONES PARA ACTUAR INDEPENDIENTEMENTE DEL DESEO
}

\author{
Isabel Victoria Lucena Cid $^{1}$ \\ Universidad Pablo de Olavide, Sevilla
}

\begin{abstract}
Resumen.- Este artículo analiza la tesis searliana según la cual todo poder político representa un poder deóntico relacionado con los derechos, los deberes, las obligaciones, las autorizaciones, los permisos, la autoridad, etc. Esta concepción nos conduce a entender el poder y las funciones de estatus como un fenómeno irremediablemente vinculado a la aceptación colectiva y las reglas constitutivas. Nociones como la constitución lingüística de los poderes deónticos, las razones para actuar independientemente del deseo, la racionalidad normativa y la aceptación colectiva de los sistemas políticos, constituyen algunas de las piedras angulares que se desarrollan en este trabajo dentro de un marco conceptual cuya visión realista de lo social, institucional y político tiene importantes implicaciones en el ámbito de la filosofía jurídica, política y moral.
\end{abstract}

\begin{abstract}
Abstrac.- This article analyzes Searle's thesis according to which all political power represents a deontic power related to rights, duties, obligations, authorizations, permissions, authority, etc. This conception leads to understand to us the power and the constituent functions of status irremediably tie to the collective acceptance and constitutive rules. Notions like linguistic constitution of deontic powers, the reasons to act independently of desire, the normative rationality and the collective acceptance of the political systems, constitute some of angular stones of a conceptual frame whose social, institutional and politic realistic vision have important implications in the scope of the legal, political and moral philosophy.
\end{abstract}

Key words: Policy, deontic power, institutional facts, political commitment, normative rationality, political system, collective acceptance, function of status

\section{Introducción}

En el año 2003 John Searle publicó un trabajo titulado "Social Ontology and Political Power", y ese mismo año apareció bajo el título "Ontologia Sociale e Potere Politico" en el volumen colectivo a cargo de Paolo di Lucía, Ontologia sociale. Potere deontico e regole costitutive ${ }^{3}$. El objetivo de Searle es explicar "la ontología del poder político" y "el papel del lenguaje en la constitución de dicho poder". La tesis principal de su libro La construcción de la realidad social comporta implícitamente una ontología política, o al menos, una relación entre una posible filosofía política y la filosofía del lenguaje. La pregunta que planteaba en aquella ocasión pretendía responder al hecho de ¿cómo reconciliar una determinada concepción que tenemos de nosotros mismo, como agentes conscientes, inteligentes, libres, sociales y políticos, con una concepción del mundo en virtud de la cual éste está constituido por partículas

\footnotetext{
${ }^{1}$ Profesora de Filosofía del Derecho de la Universidad Pablo de Olavide, Sevilla

${ }^{2}$ (2003) SCHMITT, F. F. (ed.), Socializing Metaphysics: The nature of social reality, Lanham, MD: Rowlan and Littlefield. pp. 195-210

${ }^{3}$ (2003) SEARLE, John R. "Ontologia sociale e potere político" en DI LUCIA, Paolo, Ontologia sociale. Potere deontico e regole costitutive. Macerata: Quodlibert, pp. 27-44. Cfr. SEARLE, John R. 2004, Libertad y neurobiología. Reflexiones sobre el libre albedrío, el lenguaje y el poder político. Barcelona: Paidós.
} 
físicas desprovistos de inteligencia y de significación, sometidas a campos de fuerzas? En este nuevo trabajo da un paso más y vuelve a plantear la misma cuestión introduciendo un nuevo elemento: ¿cómo puede existir una realidad política en un mundo constituido por partículas físicas?

Con objeto de responder a esta nueva pregunta, Searle retoma los postulados ontológicos descritos en su obra La construcción de la realidad social y vuelve a establecer las distinciones ontológicas y epistemológicas que le sirvieron de base para explicar los hechos institucionales y la realidad institucional. El argumento lo exponía entonces de la siguiente manera: ciertos elementos de la realidad son independientes del observador: fuerza, masa, atracción gravitatoria, fotosíntesis, enlace químico; otros elementos, por el contrario, son relativos al observador y su existencia depende de las actitudes, los pensamientos y de la intencionalidad de los observadores, los usuarios, los creadores, diseñadores, comparadores, vendedores o, de manera más general, de agentes intencionales conscientes. Ejemplos de elementos que dependen del observador son el dinero, la propiedad, el matrimonio, el lenguaje, etc. ${ }^{4}$.

A esta distinción Searle añade otra más basada en la objetividad y la subjetividad epistémica por un lado, y en la objetividad y la subjetividad ontológica, por otro. La objetividad y subjetividad epistémica son propiedades de las aserciones. En este sentido, una aserción puede determinarse de manera independiente del sentimiento, las actitudes y las preferencias, etc., de quienes las hacen o de quienes las interpretan. Decir, por ejemplo, que "Zapatero es el actual presidente de España" es epistémicamente objetiva, sin embargo, decir que "Zapatero es mejor presidente que su antecesor Aznar", es epistémicamente subjetiva. En lo que respecta a la objetividad ontológica y la subjetividad ontológica, éstas son propiedades de la realidad. De este modo, los dolores y el hambre, por ejemplo, son ontológicamente subjetivos porque su existencia depende del hecho de que los experimenta un sujeto humano o un animal. Sin embargo, las montañas, las playas y las moléculas son ontológicamente objetivas ya que su existencia no depende de experiencias subjetivas.

La justificación de estas distinciones en el marco de la actual discusión le lleva a Searle a concluir que "prácticamente toda nuestra realidad política es relativa al observador. Unas elecciones, un parlamento, un jefe de gobierno o una revolución, por ejemplo, son lo que son únicamente si la gente adopta ciertas actitudes al respecto. De ahí que todos los fenómenos sociales o políticos contengan una parte de subjetividad ontológica. Ahora bien, la subjetividad ontológica como tal no implica la subjetividad epistémica. Puede existir un ámbito como la política o la economía dentro del cual las entidades sean ontológicamente subjetivas, aunque a propósito de ellas puedan siempre hacerse aserciones epistémicamente objetivas. De este modo, la presidencia de EEUU es un fenómeno relativo a un observador, es ontológicamente

\footnotetext{
${ }^{4}$ (2003) SEARLE, John, R., "Ontologia sociales y potere politico" op. cit. pág. 28, y (2004) SEARLE, John R., Libertad y neurobiología. Reflexiones sobre el libre albedrío, el lenguaje y el poder político, op. cit. pág. 93.
} 
objetiva. Por el contrario: el hecho de que Barack Obama sea actualmente el presidente de los EEUU es un hecho epistémicamente objetivo ${ }^{5}$.

Basándonos en las anteriores consideraciones, nos proponemos examinar en este trabajo la visión searliana de la realidad política. Para ello, retomamos una serie de presupuestos sobre los que Searle articula la tesis medular de su ontología política: todo poder político es una cuestión de funciones de estatus y por esta razón todo poder político es un poder deóntico. Dado que todo poder político es una cuestión de funciones de estatus, todo poder político, aunque se ejerza desde arriba, viene de abajo. Los sistemas de funciones de estatus funcionan, al menos en parte, porque el reconocimiento de los poderes deónticos nos provee de razones para actuar independientes del deseo. Estos principios nos ofrecen, como tendremos ocasión de ver, una explicación o justificación del aparato conceptual en virtud del cual se deduce el paso de los hechos brutos a los hechos sociales e institucionales y de ahí a la especificidad de los hechos políticos.

\section{2.- La Concepción Searliana del poder Político}

El propósito de Searle en su trabajo "Ontología social y poder político" no es contribuir a la discusión de la filosofía política occidental, sino explorar algunas de las relaciones que existen entre la ontología de la realidad social y la específica forma de realidad social que supone el poder político. Su objetivo es mostrar cómo la realidad política es un caso especial de la realidad social e institucional. Algunas de las nociones fundamentales que usa para describir y analizar la naturaleza de la realidad social e institucional podrían darnos ideas sobre la naturaleza de la realidad política. A este efecto, destacamos cuatro categorías que podrían ayudar en esta empresa. La primera de ellas, es la noción de función de estatus junto a la de hechos institucionales y poderes deónticos. Asociada a estas nociones se encuentra la de aceptación colectiva, que constituyen y mantienen las funciones de estatus. La tercera idea está relacionada con el papel del lenguaje en la constitución de los fenómenos sociales y políticos. Y por último, la cuarta categoría está relacionada con la peculiar habilidad humana de crear razones para actuar independientes del deseo. Searle atribuye a los seres humanos la capacidad de reconocer y estar motivados por razones para la acción que no responden a sus primeras inclinaciones, deseos o intereses. Esta capacidad constituye una de las razones fundamentales de la existencia de la civilización humana y, a fortiori, la que posibilita organizarse políticamente ${ }^{6}$. Aunque cada una de estas ideas se explican por sí mismas, necesitamos de todas ellas para comprender la propuesta ontológica sobre el poder político searliano.

Sobre la base de los distintos argumentos expuestos, examinaremos estos postulados con el fin de responder a la cuestión que plantea Searle en los

\footnotetext{
${ }^{5}$ Vid. (2004) SEARLE, John R., Libertad y neurobiología. Reflexiones sobre el libre albedrío, el lenguaje y el poder político, op. cit. pág. 94

${ }^{6}$ SEARLE, John R. "Ontologia sociale e potere politico" op. cit. pág. 30. Vid. (2004) SEARLE, John R., Libertad y neurobiología. Reflexiones sobre el libre albedrío, el lenguaje y el poder político, op. cit. pág. 107
} 
siguientes términos: ¿qué tenemos que añadir a los hechos sociales para que lleguen a ser hechos políticos?

\subsection{El Poder Político como Poder Deóntico}

La tesis según la cual "todo poder político es cuestión de funciones de estatus, razón por la cual todo poder político es un poder deóntico", representa el eje central sobre el que se desarrollan los demás principios que conforman el contenido esencial del trabajo searliano "Ontología social y poder político". Los poderes deónticos tienen que ver con los derechos, los deberes, las obligaciones, las autorizaciones, los permisos, la autoridad, etc. El poder de los dirigentes del partido local y del consejo municipal, así como el poder de las grandes figuras (presidentes, jefes de gobierno, miembros del congreso, o del tribunal supremo) derivan todos por igual del hecho de que esas entidades poseen funciones de estatus reconocidas ${ }^{7}$.

En La construcción de la realidad social Searle utiliza la terminología de poder convencional para distinguirlo del poder bruto aunque, como él mismo admite, a menudo conceder poder convencional significa autorizar el uso del poder bruto, como sería el caso de los cuerpos de seguridad del Estado en casos de excepción. No obstante, Searle argumenta que el uso de la violencia por parte de la policía y del poder militar se contrapone al poder político. De igual modo, los conflictos entre grupos étnicos y religiosos, la violencia generada por las ideologías, el terrorismo internacional, la guerra no declarada entre estados, no pueden ser considerados políticos. De este modo, Searle contrapone la estructura lógica del poder deóntico a la estructura lógica del poder fundado sobre la fuerza.

Ante este argumento, Oppenheim se manifiesta en desacuerdo con el hecho de que el poder físico bruto del más fuerte sobre el más débil deba ser distinto del poder político ${ }^{8}$. Es más, considera que la caracterización de Searle de poder político como esencialmente deóntico no violento, no egoísta es una representación idealizada de las democracias occidentales. Ciertamente, sólo en los sistemas democráticos constitucionales el individuo es la fuente de cada poder político, pero sólo en teoría. En opinión de Oppenheim, casi todos (sino todos) los actos de ejercicio de poder político (y la respuesta a ellos) son hechos basados en el interés personal, y los conflictos de naturaleza política son generalmente o no resueltos del todo o resueltos mediante el uso de la fuerza bruta ${ }^{9}$.

\footnotetext{
${ }^{7}$ Ibíd,. pág. 108

${ }^{8}$ Cfr. OPPENHEIM, Felix, E. "Potere Bruto e potere deontico Una risposta a Searle" en (2003) DI LUCIA, Paolo, (ed.), Ontología Sociale..., op. cit. pp. 105-107. Es interesante este breve artículo de Felix E. Oppenheim sobre el poder bruto y el poder deóntico en respuesta a Searle cuando se pregunta ¿qué clase de poder es el poder político?"

9 OPPENHEIM, Felix, E. "Potere Bruto e potere deontico" Una risposta a Searle. en (2003) DI LUCIA, Paolo, (ed.), Ontología Sociale..., op. cit. pp. 106-107
} 
La contraposición entre el poder deóntico y el poder bruto, está basada en la distinción entre hechos brutos y hechos institucionales ${ }^{10}$ según la cual la estructura lógica básica de los hechos institucionales tiene la forma " $X$ cuenta como $Y$ en el contexto C", fórmula que pone de relieve las reglas constitutivas que nos posibilita crear los hechos institucionales. Junto a esta caracterización, Searle ofrece otra formula que explica la creación de poderes básicos en la sociedad, centrándose en la forma general del contenido de la función de estatus de $\mathrm{Y}$. Si "el contenido de $\mathrm{Y}$ viene impuesto al elemento $\mathrm{X}$ por aceptación colectiva, esas aceptaciones colectivas (reconocimientos, creencias, etc.) deben tener algún contenido; y lo que sugiero es que para una amplia clase de casos el contenido tiene que ver con alguna modalidad de poder convencional en la que el sujeto se relaciona con algún tipo de acción o con algún curso de acciones (...). Puesto que el poder es siempre poder para hacer algo o de impedir que algún otro haga algo, el contenido proposicional de las funciones de estatus de poder es siempre en parte que (S hace $A)^{\prime \prime 11}$. Donde $S$ representa a una persona y $A$ una acción o una actividad. La estructura primitiva de la intencionalidad colectiva $X$ cuenta como $Y$ en $C$ se convierte ahora en la estructura básica del poder convencional: Nosotros aceptamos (S tiene poder (S hace $A$ ).

¿Qué relación existe entre ambas fórmulas: $X$ cuenta como $Y$ en $C$ y Nosotros aceptamos ( $S$ tiene poder ( $S$ hace $A$ )? La respuesta que ofrece Searle es que no aceptamos solamente que alguien tiene poder, sino que aceptamos que tiene poder en virtud de su estatus institucional. Un ejemplo de $X$ cuenta como $Y$ en $C$ sería: satisfacer ciertas condiciones hace posible que alguien sea Presidente del Estado. Pero una vez que hemos aceptado que alguien es el Presidente, aceptamos también que tiene poder para realizar ciertas cosas. Tiene el poder positivo de mandar sobre las fuerzas armadas, pero también tiene el poder negativo, es decir, la obligación de gobernar la nación. Tiene el derecho de mandar sobre el ejército y las fuerzas de seguridad y tiene el deber de dirigir el gobierno. El énfasis sobre la aceptación colectiva se refleja en el análisis que realiza Searle del poder convencional: aceptamos que $S$ tiene poder ( $S$ hace $A$ ) porque $S=X$, y nosotros aceptamos que $X$ cuenta como $Y$, y que la función de estatus conlleva el reconocimiento de los poderes deónticos ${ }^{12}$.

Searle distingue varios tipos de poder convencional: simbólico, deóntico, honorífico y procedimental. En nuestro caso nos centraremos en el tipo de poder convencional normativo (deóntico), es decir, aquellos poderes que son

\footnotetext{
${ }^{10}$ En opinión de Alarcón, en su combate contra "la falacia de la falacia naturalista" Searle distingue dos tipos de deberes "los 'deberes categóricos' y los 'deberes hipotéticos'. Searle ha basado su 'antidivisionismo' en la partición de la realidad en dos áreas, la de los hechos institucionales y la de los hechos brutos. A diferencia de los hechos brutos, los hechos institucionales presuponen la existencia de determinadas instituciones, compuestas por un conjunto de reglas 'constitutivas', por un conjunto de reglas que crean o definen nuevas formas de conducta, que constituyen una actividad cuya existencia es dependiente, desde un punto de vista lógico de las reglas". ALARCóN, Carlos, 2001, Causalidad y normatividad, op, cit. pág. 33 11 (1997) SEARLE, John R., La construcción..., op. cit. pág. 116

12 (2006) SEARLE, John R. "Social Ontology: Some Basic Principles" en Anthropological Theory, Vol. 6 (1), op. cit. pág. 18; Cfr. (2005) SEARLE, John R. "What is an Institution? en Journal of Institutional Economics, Volume 1, Issue 01, January pp. 1-22
} 
fruto de la asignación de una función estatus específica con consecuencias en al ámbito de los derechos, responsabilidades, obligaciones, deberes, privilegios, habilitaciones, castigos, autorizaciones, permisos y otros fenómenos deónticos ${ }^{13}$. Partiendo de que el estatus $Y$ confiere (o niega) poder, Searle clasifica estos fenómenos deónticos dentro de otras dos categorías que se corresponden con la de los poderes positivos y negativos: "la primera se da cuando el agente es dotado con algún poder, certificado, autorización, habilitación, derecho, permiso o cualificación nuevos que le capacitan para hacer algo que no podría hacer de otro modo; la segunda se da cuando el agente es o está requerido, obligado, ligado por el deber, castigado, prescrito 0 forzado de algún modo a hacer algo que de otro modo no sería factible"14.

Si tenemos en cuenta "no los objetos sociales, como el dinero, las universidades o los estados, sino los agentes que operan sobre y dentro de esos objetos la distinción se establece entre lo que el agente puede hacer y lo que el agente debe ( $\mathrm{y}$ no debe) hacer, entre lo que el agente está capacitado para hacer y lo que requiere que haga como resultado de la asignación de estatus determinado por el término $Y^{\prime \prime 15}$. A esta distinción entre poderes positivos y negativos, Searle añade otras dos distinciones que se dan entre la creación y la destrucción de poderes convencionales y los poderes convencionales procedimentales y terminales. Un ejemplo de esto último sería la distinción entre recibir cierto número de votos y ganar las elecciones: obtener votos es un paso procedimental en el camino de ganar, y ganar es el término del proceso electoral. Como podemos observar, las funciones de estatus procedimientales son funciones deónticas condicionales, es decir, cuando se satisface el antecedente condicional el resultado es un paso en la jerarquía iterada de la realidad institucional.

En relación a los actos de creación y destrucción de poderes, esos actos pueden realizarse en virtud de otro poder convencional como sería el caso del matrimonio/divorcio. Es decir, en el caso en el que una acción implique la creación o destrucción del poder, este mismo acto es un ejercicio de poder

\footnotetext{
${ }^{13}$ (1997),SEARLE, John R. La construcción..., op. cit. pág. 112. Cfr. SEARLE, John R. "Human Rights" en www.socrates.berkeley.edu/ jsearle/130/HumanRights.doc. Este documento se encuentra colgado en Internet con fecha de 23 de marzo de 2007 y con el título "Chapter Six. Human Rights". En nuestra opinión forma parte del nuevo trabajo que está realizando Searle y del que sólo disponemos como primicia de este capítulo. El primer apartado del mismo trata de los derechos como funciones de estatus. Los derechos son siempre relativos al observador y dado que son funciones de estatus, son atribuidos gracias a la intencionalidad colectiva. Los derechos humanos no se descubren en la naturaleza al igual que se descubre un fenómeno como la fotosíntesis. Véase también los interesantes trabajos de (2006) MILLER, Seumas "Artefacts and Colletive Intentionality" en Techné, Vol. 9 (2) Winter, , pp.52-67; ARTOSI, Alberto "On the Notion of an Empowered Agent" en www.cirfid.unibo.it/ agsw/lea02/pp/Artosi.pdf

${ }^{14}$ (1997) SEARLE, John, R., La construcción..., op. cit. pág. 116. Alarcón clarifica esta distinción entre poderes positivos y poderes negativos diciendo que "los primero hacen referencia a deberes anankásticos, a 'poderes, certificados, autorizaciones, habilitaciones, derechos, permisos o cualificaciones' que posee el agente y le capacitan para hacer algo, y para que lo que haga cuente institucionalmente, por lo que actúan sobre él influyendo indirectamente en su comportamiento. Los segundos hacen referencia a deberes deónticos, a 'exigencias, obligaciones, vínculos, castigos, prescripciones o coacciones' que actúan sobre el agente influyendo directamente en su comportamiento. ALARCÓN, Carlos, 2001, Causalidad y Normatividad, Sevilla: MAd, pág. 104

${ }^{15}$ (1997) SEARLE, John, R. , La construcción..., op. cit. pág. 113
} 
convencional. En la destrucción de un poder convencional "la negación opera sobre la aceptación colectiva, no el contenido de la aceptación"16.

Como resultado de su investigación sobre la clasificación de los poderes institucionales en simbólicos, deónticos, honoríficos y procedimentales, Searle concluye que desde el punto de vista de la estructura lógica de la realidad social, lo único que tenemos son creaciones y destrucciones de poderes convencionales que pueden ser simbólicos u honoríficos, negativos o positivos y condicionales. Algunos de estos poderes son colectivos y otros son individuales y en último caso representan variaciones sobre iteraciones de la estructura básica ${ }^{17}$.

Sobre la base de estos argumentos, Searle considera que la estructura básica del poder nos permite captar todos los rasgos lógicos del contenido intencional de la función de estatus $Y$, en la fórmula " $X$ cuenta como $Y$ ", demostrándonos "que la enorme complejidad del cuerpo de la realidad institucional tiene un esqueleto muy simple"18. Sin embargo, a pesar de la coherencia lógica de su explicación, surgen cuestiones problemáticas en torno a la distinción entre poderes positivos y negativos, sobre la analogía que presenta Searle entre la dimensión deóntica y la dimensión de poder, y entre autoridad y poder ${ }^{19}$. Por otro lado, el papel que juega la noción de regla constitutiva no queda muy clara dentro de la estructura lógica del poder convencional. Para Searle, las reglas constitutivas confieren poder a través de la atribución de un estatus y una función. El problema es que Searle no explica de qué manera sucede eso. Si bien es cierto que ofrece elementos teóricos que justifican los mecanismos de asignación de función basados en fórmula 'count as', no especifica cómo funcionan las reglas constitutivas como reglas que confieren poder. Por ejemplo, no desarrolla suficientemente cómo una regla constitutiva del tipo " $A$ cuenta como el oficiante de una ceremonia de matrimonio" confiere a $A$ poder (colectivamente aceptado) para unir dos personas en matrimonio.

A tenor de lo expuesto anteriormente sobre la visión searliana del poder convencional, podemos deducir que Searle se adhiere la línea de pensamiento tradicional sobre el poder entendido en términos de capacidad y funciones de estatus deónticas. Estas funciones de estatus se traducen en dos categorías amplias de poder denominadas poderes positivos y negativos. La primara de ellas, como hemos visto, se da cuando el agente está dotado con algún poder que le capacita para hacer algo que no podría hacer de otro modo. La segunda se da cuando el agente es o puede ser requerido, esto es, le prohíbe o le obliga, ligado por el deber, a hacer algo que de otro modo no sería factible.

\footnotetext{
${ }^{16}$ (1997) SEARLE, John, R., La construcción..., op. cit. pág. 118

17 (1997) SEARLE, John, R., La construcción..., op. cit. pp. 122-23

18 (1997) SEARLE, John, R., La construcción..., op. cit. pág. 123

19 ARTOSI, Alberto, "On the Notion of an Empowered Agent", www.cirfid.unibo.it/ agsw/lea02/pp/Artosi.pdf y (2004) ARTOSI, Alberto, ROTOLO, Antonino, y VIDA, Silvia "On the logical Nature of Countas Conditionals", en CERVENINI, C. (ed.) Proceedings of LEA. Bologna: Gedit pp. 9-34. Sobre esta discusión véase también (2001) ALARCON, Carlos, , Causalidad y Normatividad, op. cit, pp. 99-109.
} 


\section{Razones para actuar independientemente del deseo}

Tal y como se ha definido anteriormente, construimos la realidad social y política asignando y aceptando colectivamente funciones de estatus y las mantenemos a través del trasfondo ${ }^{20}$. Como hemos tenido ocasión de apreciar anteriormente, las funciones no son rasgos intrínsecos del mundo, son siempre rasgos dependientes del observador. Los dos tipos de funciones que describe son las funciones agentivas y las no-agentivas.

El primer tipo de funciones son aquellas que tienen que ver con las funciones que le asignamos a los distintos objetos y fenómenos de la realidad. Son estas funciones agentivas las que Searle denomina 'funciones de estatus' cuya misión es 'representar', 'simbolizar', 'contar como' y de modo general, 'significar'. Unida a esta noción, Searle desarrolla el concepto de razones para actuar independientes del deseo en el marco de las conferencias Nicod que pronunció durante el año 2000 en el Collége de France de Paris. Dichas conferencias aparecieron luego en una versión más elaborada bajo el título de Razones para actuar. Una teoría del libre albedrío ${ }^{21}$. Cuando presentó aquella ponencia y redactó su libro no apreció el hecho de que algo podía ser una razón para actuar independientemente del deseo sin que el agente lo concibiera de ese modo. Ahora, en el contexto de su ontología del poder político, se propone aproximar las dos nociones y sostiene que las funciones de estatus, descritas en La construcción de la realidad social, son precisamente razones para actuar independientes del deseo. De ahí se sigue que el reconocimiento de las funciones de estatus en que se funda el poder político es en sí mismo el reconocimiento de unas razones para actuar independientemente del deseo. Lo verdaderamente llamativo aquí es que todo el sistema social y político se funda en la capacidad de los agentes humanos de reconocer razones independientes del deseo y actuar en virtud de ellas ${ }^{22}$.

Veamos más detalladamente esta tesis de Searle. Teniendo como base los hechos brutos, los hechos institucionales y políticos representan el marco donde se desarrolla nuestra actividad, ya sea individual o colectiva. A partir de este presupuesto, Searle busca explicar una racionalidad que explique nuestra actividad basada en el hecho de reconocer ciertas cosas como razones para actuar. Pero ¿en que se basan las razones para actuar independientemente del deseo?, ¿en qué consiste que $X$ sea reconocido como una razón para $Y ?^{23}$

\footnotetext{
${ }^{20}$ Searle define el concepto de trasfondo como "el conjunto de capacidades no intencionales o preintencionales que hacen posibles los estados intencionales de función" "para explicar cómo podemos relacionarnos con estructuras de desempeño de papeles como el lenguaje, la propiedad o el dinero, el matrimonio, etc., cuando no conocemos las reglas y, por tanto, no las podemos observar ni consciente ni inconscientemente, tengo que apelar a la noción (...) del trasfondo". Vid. SEARLE, John R. 1997, La construcción..., op. cit. pp. 140-141

${ }^{21}$ (2000) SEARLE, John R., Razones para actuar. Una teoría del libre albedrío, Oviedo: Ediciones Novel

${ }^{22}$ SEARLE, John R. "Ontologia sociale e potere político" en (2003)DI LUCIA, Paolo, Ontologia sociale. Potere deontico e regole costitutive. op. cit. pág. 32 (2004) SEARLE, John R., Libertad y neurobiología. Reflexiones sobre el libre albedrío, el lenguaje y el poder político. op. cit., pág. 107

${ }^{23}$ (2002) LIZ GUTIERREZ, Manuel, "Forma y contenido en las razones para actuar independientemente del deseo" en Revista Laguna, vol. 10, , pág. 88. Vid SEARLE, John R. 2000, Razones para actuar. Una teoría del libre albedrío, op. cit. Cfr. (2003) RODRIGUEZ
} 
Searle se opone al modelo clásico de racionalidad sobre las acciones humanas, modelo según el cual los actos racionales sólo pueden motivarse por un deseo o interés del agente ${ }^{24}$. Frente a esta visión, Searle sostiene que existe una brecha causal entre las creencias y deseos por un lado y la acción por otro: "la brecha donde interviene la toma racional de decisiones es, en realidad, triple. La primera brecha se da entre las razones para hacerse una idea de lo que uno va a hacer y la decisión efectiva que uno toma. La segunda se produce después de que uno se ha hecho una idea de qué hacer, en este caso tiene todavía que decidir cuándo hacerlo de modo efectivo. Y por último, en el caso de las actividades que se extienden en el tiempo, hay otra brecha entre el inicio de la acción y su continuación mediante esfuerzo voluntario continuo hasta que se la completa"25.

El modelo clásico basado en las teorías de la decisión racional o en las concepciones instrumentales de la racionalidad, únicamente atienden al primer tipo de razones, esto es, a aquellas que son dependientes de los deseos y que incluyen, por ejemplo, los intereses, los fines, preferencias, utilidades, valores aceptados, etc. Este modelo se apoya en seis principios básicos: a) las acciones racionales están causadas por creencias y deseos; b) la racionalidad consiste en seguir ciertas reglas; c) la racionalidad es una facultad cognitiva separable de otras; d) los casos de debilidad de la voluntad, o akrasis, son literalmente imposibles; e) la racionalidad práctica debe suponer siempre unos deseos, o fines, objetivos e intereses, etc.,) la racionalidad sólo es posible si esos conjuntos de deseos primarios son consistentes ${ }^{26}$.

En su obra Razones para actuar, Searle discute cada uno de estos supuestos ofreciendo distintos argumentos para definir un concepto de racionalidad no instrumental, basada en el compromiso. Con respecto al primero de ellos sostiene que las acciones racionales no pueden tener antecedentes causales suficientes, es decir, no estarían causadas por creencias y deseos. A su juicio, solo aquellos que estén bajo los efectos de sustancias tóxicas, o en condiciones extremas incontrolables, se dejan llevar por las creencias y los deseos. Por el contrario, una decisión racional está basada en la consideración de razones para hacer algo y finalmente, cuando se toma la decisión, se realiza en virtud de alguna de las razones contempladas y no por otras. Según Searle, esto entrañaría la existencia de una 'brecha' entre las razones para la acción y la decisión de actuar, es decir, a fin de que sea posible e inteligible la toma racional de decisiones, hemos de presuponer el libre albedrío. Sin libertad no tendríamos por qué emprender ningún proceso de toma de decisión ${ }^{27}$.

GONZÁLEZ, Mariano, "Esa fuerza tan especial del compromiso" en LOGOS. Anales del Seminario de Metafísica, $\mathrm{n}^{\circ}$ 36, , pp. 283-288

${ }^{24}$ Vid. (2001) BEJARANO, Teresa, "Acerca de las razones para actuar de Searle", en Thémata. Revista de Filosofía, $\mathrm{n}^{\circ}$ 26,. pp. 259-273

${ }^{25}$ (2000) SEARLE, John R. Razones para actuar. Una teoría del libre albedrío, op. cit. pp.2728

${ }^{26}$ (2002) LIZ GUTIERREZ, Manuel, "Forma y contenido en las razones para actuar independientemente del deseo" en Revista Laguna, vol. 10, pág. 88. Vid (2000) SEARLE, John R., Razones para actuar. Una teoría del libre albedrío, op. cit. pp. 20-25

${ }^{27}$ (2002) LIZ GUTIERREZ, Manuel, "Forma y contenido en las razones para actuar independientemente del deseo" op. cit. pág. 89. (2000) SEARLE, John R., Razones para actuar. Una teoría del libre albedrío, op. cit. pág. 25 
En relación al segundo supuesto, Searle sostiene que la racionalidad no consiste en seguir reglas. A este propósito dice que cualquiera "puede comportarse racionalmente sin conocer las reglas que determinan la racionalidad e incluso sin ser conscientes de que está siguiendo las reglas" ${ }^{28}$. Afirma que la racionalidad no está constituida ni definida por ningún conjunto de reglas. La función de las reglas es sistematizar lo que de por sí es válido y lo que garantiza esa validez son los contenidos semánticos ${ }^{29}$.

Al tercer supuesto del modelo clásico de racionalidad, responde argumentando que la racionalidad está incorporada a la estructura general de la intencionalidad, es decir, "no puede haber una facultad separada de la racionalidad distinta de capacidades tales como aquellas que tienen que ver con el lenguaje, el pensamiento, la percepción y las distintas formas de intencionalidad; las constricciones racionales están incorporadas en, son internas a, la estructura de la intencionalidad en general, y del lenguaje en particular"30. Así, en opinión de Searle, no se puede hacer un enunciado sin preocuparse por cuestiones del tipo ¿es verdadero o es falso?, ¿es consistente 0 es inconsistente con las cosas que he dicho? De este modo, "las constricciones de la racionalidad no son una facultad que aparece además de la intencionalidad del lenguaje. Una vez que se tiene intencionalidad y lenguaje, se tienen ya fenómenos que, interna y constitutivamente, tiene las constricciones de la racionalidad"31

En cuanto al cuarto punto, Searle argumenta que la debilidad de la voluntad es siempre posible. Esta debilidad de la voluntad surge del hecho de que en cualquier punto el fenómeno de la brecha (de la libertad) nos presenta un número indefinido de opciones abiertas capaces de atraernos aún cuando pensábamos, en un determinado momento, que las íbamos a rechazar. El fenómeno de la 'brecha', de la libertad de poder elegir, explica por qué es tan común la debilidad de la voluntad.

El quinto postulado lo rechaza Searle en base a su crítica a la tesis clásica de que un acto racional sólo puede motivarse por un deseo, donde 'deseo' incluye valores morales y valoraciones. Los deseos no tienen por qué estar siempre centrados en uno mismo sino que existen razones para actuar independientemente del deseo, razones externas que sobrepasan el marco de una racionalidad meramente instrumental, y la sitúan en un marco teleológico. Las razones independientes del deseo sirven para enjuiciar y someter a crítica a los propios deseos ${ }^{32}$. En este punto, Searle atribuye la tesis de que no existen razones para actuar independientes del deseo a la falacia naturalista de Hume: la imposibilidad de derivar de un 'es' un 'debe'. Sobre esto afirma que

\footnotetext{
${ }^{28}(2000)$ SEARLE, John R., Razones para actuar. Una teoría del libre albedrío, op. cit. pág. 35. Volveremos sobre este punto más adelante.

${ }^{29}$ (2002) LIZ GUTIERREZ, Manuel, "Forma y contenido en las razones para actuar independientemente del deseo" op. cit. pág. 89

${ }^{30}(2000)$ SEARLE, John R., Razones para actuar. Una teoría del libre albedrío, op. cit. pp. 35

${ }^{31}$ (2000) SEARLE, John R, Razones para actuar. Una teoría del libre albedrío, op. cit. pp. 36

${ }^{32}$ (2002) LIZ GUTIERREZ, Manuel, "Forma y contenido en las razones para actuar independientemente del deseo" op. cit. pág. 90. (2000) SEARLE, John R., Razones para actuar. Una teoría del libre albedrío, op. cit. pp. 42-42
} 
"los enunciados con 'debe' expresan razones para la acción. Decir que alguien debería hacer algo implica que hay una razón para que lo haga" 33 .

Por último, sobre el sexto supuesto, Searle considera que es normal e inevitable que las razones para actuar entren en conflicto y que la racionalidad consiste justamente en deliberar y tomar decisiones, en determinadas circunstancias, desde una situación de inconsistencia y conflicto ${ }^{34}$.

Estas objeciones a los principios constitutivos del modelo clásico de racionalidad junto a la explicación que ofrece sobre la estructura básica de la intencionalidad, entendida como acción y significado ${ }^{35}$, sitúan a Searle en condiciones de abordar la estructura lógica de las razones y responder a la cuestión: ¿cómo creamos razones para actuar independientes del deseo? y ¿qué alcance tiene esta tesis en su concepción del poder político? En primer lugar, para Searle, las razones son entidades proposicionalmente estructuradas. Dar razón de algo es ofrecer una explicación, una respuesta a determinadas preguntas. Podrían ser hechos del mundo tales como el hecho de que está lloviendo, o estados intencionales proposicionales tales como mi deseo de no mojarme, aunque también podrían ser entidades proposicionalmente estructuradas que no fuesen ni hechos ni estados intencionales, esto es, entidades como las obligaciones, compromisos, requisitos o necesidades, etc. Searle denomina a este tipo de hechos "factitivos". De lo cual deduce que las razones son entidades factitivas y su estructura proposicional "las capacita para tener un carácter relacional al menos en cuatro sentidos: 1) las razones son siempre razones para algo y para explicar por qué sucede ese algo, 2) son razones para un sujeto, 3) son epistémicamente accesibles a fin de tomar parte en una deliberación y 4) están siempre relacionadas con otras razones" ${ }^{36}$.

Searle apoya esta teoría sobre conceptos e ideas que están presentes en sus obras anteriores, pero en Razones para actuar proporciona, además, nuevos conceptos y traza varias distinciones que nos servirá posteriormente para comprender su tesis sobre las razones para actuar independientes del deseo.

\footnotetext{
33."De este modo la afirmación de Hume equivale a sostener que los enunciados que aseveran la existencia de razones para la acción no pueden derivarse de enunciados sobre cómo son las cosas en el mundo. Pero cómo son las cosas tiene que ver con cómo son las cosas del mundo tal como éste existe independientemente de conjunto motivacional del agente. Así pues, de acuerdo con esta interpretación, el que de una afirmación acerca de cómo son las cosas del mundo no pueda implicar la existencia de razón alguna en el conjunto motivacional del agente (no se puede derivar un 'debe' de un 'es') es la misma afirmación que la que sostiene que no hay hechos del mundo que sean independiente del agente y que, por sí mismo constituyan razones para la acción (no hay razones externas)".

${ }^{34}$ (2000) SEARLE, John R., Razones para actuar. Una teoría del libre albedrío, op. cit. pág. 45; (2002) LIZ GUTIERREZ, Manuel, "Forma y contenido en las razones para actuar independientemente del deseo" op. cit. pág. 90

${ }^{35}$ Véase sobre este aspecto el libro de Searle Intencionalidad. En esta obra vuelve retomar este objeto de análisis en el capítulo segundo de Razones para actuar. Una teoría del libre albedrío, donde se centra en los tres aspectos que conforma su teoría de la intencionalidad: la deliberación previa, la intención previa y la intención-en-la-acción.

${ }^{36}$ (2002) LIZ GUTIERREZ, Manuel, "Forma y contenido en las razones para actuar independientemente del deseo" op. cit. pág. 92. Vid. (2000) SEARLE, John R., Razones para actuar. Una teoría del libre albedrío, op. cit. pp. 121-126
} 
Una de estas distinciones es la que establece entre las razones externas y las razones internas para actuar. Las primeras de ellas, son entidades factitivas que pueden funcionar como razones para un agente si son adecuadamente reconocidas y aceptadas como tales razones. Cuando esto ocurre, la razón pasa a ser una razón interna. La otra distinción está relacionada como las razones totales y las razones parciales ${ }^{37}$. Las razones totales tienen que contener al menos un motivador, es decir, los motivadores de las acciones serían conjuntos de elementos factitivos con dirección de ajuste de mundo-amente $^{38}$. Los motivadores pueden ser internos y externos, lo primeros serían los deseos, la esperanza, el temor, la vergüenza, el orgullo, el asco, la sed, el hambre y el placer, etc. Los motivadores externos, por su parte, incluyen las obligaciones, las necesidades, los deberes, los compromisos, etc. Los motivadores son ontológicamente subjetivos al ser relativos a un sujeto, pero a la vez pueden ser epistémicamente objetivos ${ }^{39}$.

En definitiva, creamos razones para actuar independientemente del deseo creando motivadores externos que nos implican sean cuales sean nuestros deseos. En el caso de las instituciones sociales y políticas reconocemos como razones para actuar las funciones de estatus que nos comprometen ${ }^{40}$ en la

\footnotetext{
37 "Las razones totales serían conjuntos de entidades factitivas y las razones parciales serían parte de una razón total" (2002) LIZ GUTIERREZ, Manuel, "Forma y contenido en las razones para actuar independientemente del deseo" op. cit. pág. 91.

${ }^{38}$ Searle nos ofrece una explicación sobre la capacidad humana de relacionarse con el mundo real mediante la Intencionalidad. Del mismo modo que los actos de habla, los estado mentales intencionales tienen una dirección de ajuste (no ya entre las palabras y el mundo, sino entre mente y mundo), que depende del modo psicológico. Searle considera que "los diferentes tipos estados intencionales relacionan el contenido proposicional del mundo real con lo que podríamos llamar diferentes obligaciones de ajuste" ${ }^{38}$. Como resultado de esta afirmación obtenemos que tanto las creencias como las hipótesis serán verdaderas o falsas siempre y cuando el mundo sea tal y como las creencias lo representen. Por otro lado, los deseos e intenciones carecen de esta tipo de dirección de ajuste, ya que como asevera Searle, "si un deseo o una intención no se satisfacen, no es responsabilidad de, expresémoslo así, del deseo o de la intención, sino del mundo, que es el que no concuerda con el contenido del deseo o de la intención". El paralelismo entre la teoría de la Intencionalidad y los actos de hablas que subrayábamos anteriormente, es evidente. Las fuerzas ilocucionarias son iguales que los "modos psicológicos", y ambos poseen dirección de ajuste. En suma, Searle concluye diciendo que "las creencias, percepciones y recuerdos tienen la forma de mente-mundo, porque su objetivo es representarse cómo son las cosas; los deseos e intenciones tienen la dirección de ajuste mundo-mente, porque su objetivo no es representarse cómo son las cosas, sino cómo desearíamos que fueran o cómo planeamos que sean".

${ }_{39}$ (2002) LIZ GUTIERREZ, Manuel, "Forma y contenido en las razones para actuar independientemente del deseo" op. cit. pág. 93. (2000) SEARLE, John R., Razones para actuar. Una teoría del libre albedrío, op. cit. pág. 140

${ }^{40}$ De este modo define Searle el compromiso: "Los compromisos son entidades factitivas que reúnen nuestra condición para ser razones para la acción. Un compromiso tiene un contenido proposicional y una dirección de ajuste descendente. De este modo, si tengo el compromiso de ir a Avilés la próxima semana, el contenido proposicional es 'que vaya a Avilés la próxima semana', la dirección de ajuste es ascendente. El compromiso se satisface sólo si voy efectivamente a Avilés. Sin intentar dar 'condiciones necesarias y suficientes' podemos decir esto: un compromiso es la adopción de un curso de acción (u otro contenido intencional; uno puede, por ejemplo, tener un compromiso con creencias y deseos) donde la propia naturaleza de esa adopción proporciona una razón independiente del deseo para llevar a cabo el curso de la acción de que se trate". (2000) SEARLE, John R., Razones para actuar. Una teoría del libre albedrío, op. cit. pág. 201
} 
realidad social, a veces incluso más allá de nuestros deseos ${ }^{41}$. Desde esta perspectiva, las funciones de estatus reconocidas se convierten en una razón para la acción independiente del deseo. Como dice Liz Gutiérrez, "su reconocimiento como motivadores sería ya su reconocimiento como razones para actuar. A partir de tal reconocimiento, el agente delibera desde la brecha, sopesa las diferentes razones que reconoce, y forma una intención de actuar"42.

Un caso paradigmático de la creación de razones para actuar independientemente del deseo es el de la institución de la promesa. Esta vez, Searle formula la cuestión de la siguiente manera: ¿qué razón tengo para mantener una promesa?, y responde diciendo que "las promesas, por definición crean obligaciones, y las obligaciones son, por definición, razones para la acción". El sujeto que promete crea un motivador externo, una razón para actuar que puede ir en contra de sus propios deseos y que le obliga. Searle profundiza en esta idea y dice que "cuando hago una promesa, la institución de prometer es sólo el vehículo, el instrumento que uso para crear una razón. La obligación de mantener una promesa deriva del hecho de que, al prometer creo, de manera libre y voluntaria, una razón para mí mismo. El libre ejercicio de la voluntad puede vincularla, y esto es un asunto lógico que no tiene nada que ver con las 'instituciones', 'actitudes morales' o 'emisiones evaluativas'. Esta es la razón por la que el esclavo no tiene razón alguna para obedecer a su propietario, excepto razones de prudencia, pues no ha vinculado su voluntad por medio de un libre ejercicio de su voluntad"43.

El mundo social en general y el político en particular están llenos de entidades factitivas que actúan como motivadores externos que nos invitan a su reconocimiento como tales motivadores (el deber o la obligación política pueden representar razones para actuar independientes del deseo). Las instituciones sociales y políticas constituyen un complejo entramado de entidades que cuentan como obligaciones, deberes, exigencias, compromisos y necesidades, etc. Estas razones para actuar, o motivadores externos o funciones de estatus, intencional y colectivamente creados, han de ser reconocidos, aceptados y mantenidos.

No siempre, sin embargo, los seres humanos actúan a la luz de razones independientes de sus deseos. Un ejemplo de esto lo encontramos en el marco de las relaciones lógicas entre el poder político y el poder económico. Tanto los sistemas económicos como los políticos son sistemas de funciones de estatus. Como hemos visto, al sistema político corresponde a la maquinaria gubernamental. El sistema económico, por el contrario, se corresponde con el aparato económico que crea y distribuye los bienes. Por más que las estructuras lógicas respectiva se parezcan, los sistemas motivacionales

\footnotetext{
${ }^{41}$ SEARLE, John R. 2000, Razones para actuar. Una teoría del libre albedrío, op. cit. pág. 221 y ss; (2002) LIZ GUTIERREZ, Manuel, "Forma y contenido en las razones para actuar independientemente del deseo" op. cit. pág. 94

${ }^{42}$ (2002) LIZ GUTIERREZ, Manuel, "Forma y contenido en las razones para actuar independientemente del deseo" op. cit. pág. 93. (2000) SEARLE, John R., Razones para actuar. Una teoría del libre albedrío, op. cit. pp. 142-143

${ }^{43}$ (2000) SEARLE, John R., Razones para actuar. Una teoría del libre albedrío, op. cit. pág. 226
} 
racionales que aparecen en cada caso difieren de manera significativa. El poder económico está relacionado esencialmente con el hecho de ser capaz de repartir ventajas y sanciones económicas. El poder político a menudo actúa también así, sobre todo en los estados que desarrollan fuertes políticas de bienestar social o compensaciones económicas a grupos más desfavorecidos, pero no siempre. Searle considera que este hecho ha propiciado que aparezcan toda una serie de teorías confusas que intentan examinar las relaciones políticas como si tuvieran la misma estructura lógica que las relaciones económicas. Ahora bien, las razones para actuar fundadas en el deseo 0 en el interés como las económicas, aun cuando participen de un sistema deóntico, no son deontológicas. El punto importante sobre el que hay que insistir es que la esencia del poder político es un poder deóntico. Esta noción, dicho sea de paso, está en el origen de una intuición que movía a los teóricos del contrato social. Éstos pensaban que no había manera de tener un sistema de obligaciones políticas ni, de hecho, manera de tener una sociedad política sin algo así como una promesa, una promesa o un compromiso original que creara el sistema deóntico necesario para mantener la realidad política.

En suma, el hecho de reconocer la validez o la aceptación de la función de estatus, o de reconocer simplemente su existencia, confiere al agente una razón para actuar independientemente del deseo. Nunca se insistirá demasiado en la importancia de este hecho, ya que con él se explica la diferencia entre los seres humanos y los demás animales sociales. Este es un punto importante en la cuestión de la motivación: una vez que se reconoce que uno tiene una razón válida para hacer algo, aunque uno no quiera hacerlo, se tiene al menos una razón para querer hacerlo. Entre los casos que pueden constituir razones para actuar independiente del deseo, estaría, por ejemplo, la obligación de estar en el lugar de trabajo a la hora fijada en el contrato, de asistir a las clases en la universidad, aunque nuestros deseos e intereses no coincidan con estas obligaciones. Así, en el caso de la sociedad humana, y contrariamente, a las sociedades animales, las razones pueden motivar a los deseos y no todas las razones proceden de los deseos. Es importante, sin embargo, ver que en lo tocante a la realidad política no tenemos necesidad de construir o crear explícitamente razones para actuar independientes del deseo, como sucede cuando hacemos promesas o asumimos otros compromisos de índole personal, cualquiera que sean. El simple hecho de reconocer como válido u obligatorio un conjunto de hechos institucionales crea razones para actuar que son independientes de nuestros deseos.

Si bien es verdad que los poderes deónticos (las obligaciones, deberes, exigencias, imposiciones, etc.) podrían ser razones para la acción independientemente del deseo, Oppenheim sostiene que las relaciones de poder institucionales implican, a su vez, intereses personales. Esto es verdad especialmente si nos fijamos en el poder político ejercitado por la autoridad política (gobierno) sobre los ciudadanos. Estos últimos pueden satisfacer las normas jurídicas, simplemente, porque las reconoce dotadas de autoridad, o para evitar sanciones o porque el derecho coincide con los intereses personales ${ }^{44}$.

\footnotetext{
${ }^{44}$ OPPENHEIM, Felix, "Potere bruto e potere político. Una risposta a Searle" en (2003) DI
} LUCIA, Paolo, (ed), Ontologia sociale..., op. cit. pág. 106 


\subsection{Hacia un modelo de racionalidad normativa}

Volvamos de nuevo sobre el argumento searliano según el cual cualquiera puede comportarse racionalmente sin conocer las reglas que determinan la racionalidad e incluso sin ser conscientes de que se están siguiendo reglas: la racionalidad no está constituida ni definida por ningún conjunto de reglas ${ }^{45}$. Partiendo de este presupuesto, existen varias maneras de comprender la interacción entre las normas sociales y la racionalidad.

La realidad institucional y política, como vimos, descansa sobre un conjunto de reglas constitutivas. Estas reglas a diferencia de las reglas regulativas, poseen la propiedad de crear determinadas prácticas que no existirían sin estas reglas. La estructura formal de las reglas constitutivas sería $X$ cuenta como $Y$ en el contexto $C$ : cualquier hecho, físico o institucional, cumple una determinada función de estatus en un determinado contexto. Searle ha puesto de manifiesto en diversas ocasiones que los individuos no piensan "esta es la regla, así hay que aplicarla para que de lugar a un hecho institucional", sino que estas reglas subyacen y reflejan la estructura lógica de los hechos institucionales.

Esta concepción choca frontalmente con aquellas teorías sociales que postulan un enfoque de los individuos como "acatadores y seguidores de normas", es decir, que los individuos conocen y aplican conscientemente esas reglas constitutivas. ¿Cómo se explican las regularidades de la conducta humana? Searle responde de distintas maneras a esta cuestión, dependiendo de la evolución de su pensamiento manifiesto en los distintos trabajos que ha publicado. Searle intenta superar este problema acudiendo a su concepto de trasfondo. El trasfondo consiste en un conjunto de capacidades y suposiciones pre-intencionales necesarias para que los estados intencionales tengan sentido. Searle sostiene que cuando nuestro comportamiento se ajusta a las reglas constitutivas no estamos "siguiendo reglas" en el sentido wittgensteiniano, pues como este autor argumenta, la noción de observar reglas de un modo profundamente inconsciente es incoherente en sí misma. Para Searle, seguir inconscientemente una norma nos abocaría a lo que él denomina una zombie view, es decir, a la concepción de que podemos hacer algo 'virtuosa' o 'habilidosamente' siendo a la vez completamente inconscientes de lo que estamos haciendo ${ }^{46}$. La influencia del trasfondo en nuestra conducta no es normativa, y por tanto, no 'aplicamos normas', la conducta basada en disposiciones inconscientes no puede consistir en 'seguir normas', sino que, como advirtió Wittgenstein, se trata de una conducta causalmente determinada en el mismo sentido en que lo está un acto reflejo. El hecho de que nuestra conducta se ajuste a las reglas constitutivas se debe a que las capacidades y los presupuestos del trasfondo han sido causados por estas reglas, es decir, está lógicamente estructurado por reglas constitutivas. De este modo se

\footnotetext{
45 (2000) SEARLE, John R., Razones para actuar. Una teoría del libre albedrío, op. cit. pág. 35.

46 (2001).SEARLE, John, R. "Neither phenomenological description nor rational reconstruction: Replay to Dreyfus" en Revue Internationale de Philosophie, $\mathrm{n}^{\circ}$ 217, Vid (2002) NOGUERA FERRER, José Antonio, "Racionalidad y normas sociales en la teoría post-analítica de la acción" en www.selene.uab.es/_cs_gr_saps/catala/autors/xxnoguera.htm
} 
entiende por qué actuamos de 'acuerdo con normas' sin que estemos 'siguiendo normas'.

Este argumento searliano está fuera del alcance de cualquier teoría sobre la racionalidad de los sujetos. ¿De qué manera podemos introducir en este análisis la orientación racional o normativa? De nuevo hemos de acudir a una de las contribuciones más tempranas de Searle: la teoría de los actos de habla. Según esta teoría, la fuerza ilocucionaria del lenguaje es capaz de establecer vínculos normativos entre los individuos ${ }^{47}$. Este conjunto de vínculos ilocucionarios responden a su vez a la forma lógica de las reglas constitutivas al asignar funciones de estatus y crear poderes deónticos (derechos, obligaciones, deberes, etc.) que se expresan en la regla lógicamente equivalente 'aceptamos que $S$ tiene poder para hacer $Y$ en el contexto C'; por otro lado, estos vínculos, al contrario que una conducta determinada causalmente por el trasfondo, dan lugar a razones para la acción independientes del deseo, esto es, una racionalidad no instrumental sino normativa. Las normas no son seguidas irracional o inconscientemente, sino que dan lugar a razones para actuar. De todo lo cual se deduce que hay una explicación de la acción que no es una interpretación causal de la misma: es la explicación basada en las razones independientes del deseo.

Estas razones no determinan causalmente nuestra conducta, pero el hecho de que les reconozcamos validez la explica igualmente si actuamos de acuerdo con ellas: son razones no basadas en lo que estamos 'inclinados' a hacer, sino en lo que creemos que debemos hacer o tenemos que hacer, pero no porque no dejen otra opción, sino porque las consideramos cargadas de validez.

En definitiva, hay razones válidas para una acción racional que no residen en los deseos o el interés personal, sino en las relaciones y vínculos ilocucionarios y sociales que hemos creado. Por consiguiente, las normas sociales no son siempre algo pre-existentes, sino algo que podemos crear con nuestros actos de habla, y que una vez creado funciona como motivador externo de nuestra acción. Searle, consigue ver el seguimiento de normas como algo consciente y racionalmente perseguido, pero no según motivaciones instrumentales, utilitaristas o de conveniencia, sino por la convicción racional de que se debe actuar sobre la base de esas razones ${ }^{48}$.

${ }^{47}$ (2001) SEARLE, John R., Actos de Habla. Ensayo de Filosofía del Lenguaje, Madrid: Cátedra, pp. 137-160. A través del lenguaje y la interacción humana estamos continuamente superando la 'falacia naturalista' de Hume y derivando un 'debe' de un 'es', por ejemplo cuando realizamos promesas, contraemos compromisos, aceptamos roles, cargos institucionales, creamos hechos institucionales nuevos a través de declaraciones bajo circunstancias adecuadas, etc., sobre este tema véase el excelente trabajo de (2001) ALARCON, Carlos, , Causalidad y Normatividad, op. cit, pág. 87 y ss.

${ }^{48}$ (2002) NOGUERA FERRER, J. A. "Racionalidad y normas sociales en la teoría post-analítica de la acción" op. cit. http://selene.uab.es/_cs_gr_saps/catala/xgeneral2.htm 